\title{
Physiological Acute Response to High-Intensity Intermittent and Moderate-Intensity Continuous 5 km Running Performance: Implications for Training Prescription
}

\author{
by \\ Carolina Cabral-Santos ${ }^{1}$, José Gerosa-Neto ${ }^{1}$, Daniela S. Inoue ${ }^{1}$, Fabrício E. Rossi ${ }^{1}$, \\ Jason M. Cholewa², Eduardo Z. Campos', Valéria L. G. Panissa ${ }^{4}$, Fábio S. Lira ${ }^{1}$
}

The aim of this study was to investigate the physiological responses to moderate-intensity continuous and high-intensity intermittent exercise. Twelve physically active male subjects were recruited and completed a 5-km run on a treadmill in two experimental sessions in randomized order: continuously $\left(70 \% \mathrm{sVO} \mathrm{Smax}_{2}\right)$ and intermittently (1:1 min at s $V_{2} O_{2 m x}$. Oxygen uptake, excess post-exercise oxygen consumption, lactate concentration, heart rate and rating of perceived exertion data were recorded during and after each session. The lactate levels exhibited higher values immediately post-exercise than at rest (High-Intensity: $1.43 \pm 0.25$ to $7.36 \pm 2.78$; Moderate-Intensity: $1.64 \pm 1.01$ to $\left.4.05 \pm 1.52 \mathrm{mmol} \cdot \mathrm{L}^{-1}, p=0.0004\right)$, but High-Intensity promoted higher values ( $\left.p=0.001\right)$ than Moderate-Intensity. There was a difference across time on oxygen uptake at all moments tested in both groups (High-Intensity: $100.19 \pm$ 8.15L; Moderate-Intensity: $88.35 \pm 11.46, p<0.001)$. Both exercise conditions promoted increases in excess postexercise oxygen consumption (High-Intensity: $6.61 \pm 1.85$ L; Moderate-Intensity: $5.32 \pm 2.39 \mathrm{~L}, p<0.005$ ), but higher values were observed in the High-Intensity exercise protocol. High-Intensity was more effective at modifying the heart rate and rating of perceived exertion (High-Intensity: $183 \pm 12.54$ and 19; Moderate-Intensity: $172 \pm 8.5$ and 16, respectively, $p$ <0.05). In conclusion, over the same distance, Moderate-Intensity and High-Intensity exercise exhibited different lactate concentrations, heart rate and rating of perceived exertion. As expected, the metabolic contribution also differed, and High-Intensity induced higher energy expenditure, however, the total duration of the session may have to be taken into account. Moreover, when following moderate-intensity training, the percentage of $\mathrm{sVO}_{2 \max }$ and the anaerobic threshold might influence exercise and training responses.

Key words: physiologic responses, energy expenditure, lactate concentration, high intensity intermittent exercise, acute exercise, excess post-exercise oxygen uptake.

\section{Introduction}

The implementation of low to moderate intensity and long duration continuous efforts has been classically prescribed for the maintenance or improvement of aerobic capacity and health promotion in different populations (Haskell et al., 2007; Nelson et al., 2007). Several meta-analyses

have demonstrated the benefits of moderateintensity continuous exercise (MICE) on body composition, metabolic risk factors and improving maximum oxygen uptake $\left(\mathrm{VO}_{2 \max }\right)$. MICE promotes metabolic health via antiinflammatory effects, increasing the activity of

\footnotetext{
1 - Exercise and Immunometabolism Research Group, Department of Physical Education, Universidade Estadual Paulista (UNESP), São Paulo, Brazil.

2 - Department of Kinesiology, Coastal Carolina University, Conway, SC, USA.

3 - Department of Physical Education - Universidade Federal de Pernambuco, Recife - PE, Brazil.

4 - Department of Sports, School of Physical Education and Sports, University of São Paulo, São Paulo, Brazil.
} 
aerobic enzymes, intramuscular glycogen, mitochondrial and capillary densities in the muscles, oxidation of lipids in skeletal muscle and the liver as well as improvement in aerobic capacity (Ismail et al., 2012; Kelley et al., 2006; Kelley and Kelley, 2008; Thorogood et al., 2011). As such, the American College of Sports Medicine and the American Heart Association both recommend $30 \mathrm{~min}$ or more of MICE (64-76\% of maximal heart rate or $46-63 \%$ of $\mathrm{VO}_{2 \max }$ ) preferably every day of the week for protection against chronic diseases and at least 60-90 min of moderate-intensity activity daily to sustain weight loss in adults who have lost substantial body weight.

High-intensity interval exercise (HIIE) has been used as an interesting method for improving health markers, $\mathrm{VO}_{2 \max }$ and oxidative capacity, since similar or greater effects are induced during low volume high intensity exercise (i.e., $\leq 10$ minutes of intensive exercise) (Burgomaster et al., 2008; Gibala et al., 2006) when compared to the traditional MICE (vigorous intensity: $77-95 \%$ of the maximal heart rate or $64-90 \%$ of $\mathrm{VO}_{2 \max }$ ) (Garber et al., 2011). Both protocols 4-6 x $30 \mathrm{~s}$ Wingate with 4 minutes of recovery as well as 10 x $60 \mathrm{~s}$ at $90 \%$ of maximal heart rate interspersed with $60 \mathrm{~s}$ of recovery have been used for HIIT to improve glucose control and metabolic and vascular risk factors in overweight/obese sedentary men and patients with type 2 diabetes (Little et al., 2011; Whyte et al., 2010); although the $10 \times 60 \mathrm{~s}$ protocol is considered more feasible than all-out efforts for different types of populations, due to its effectiveness, safety reports and easy adherence.

When physically active subjects perform MICE, they may run for approximately $5 \mathrm{~km}$ (mean of $70 \%$ of maximal aerobic speed), while the HIIE volume is significantly lower than that performed during MICE (Burgomaster et al., 2008; Gibala et al., 2006), which induces a reduction in energy expenditure during training $(352 \pm 34$ versus $547 \pm 65 \mathrm{~kJ}$ respectively; $\mathrm{p}<0.001$ ), without a difference in excess post-exercise oxygen consumption (EPOC) (Skelly et al., 2014). However, Skelly et al. (2014) observed relatively lower intensity during the HIIE (i.e., $77 \pm 3 \%$ of peak power output) than suggested.

In this sense, aiming to induce higher aerobic adaptation to training, no study has investigated whether HIIE training performed at higher intensity (i.e., $100 \%$ of maximal aerobic speed) and with the same volume as MICE results in different physiological responses and metabolic adaptations during and after training, respectively. Thus, the objective of this study was to compare the effects of $5 \mathrm{~km}$ MICE and HIIE on the physiological responses in young adults. Our hypothesis was that HIIE would present greater physiological responses than MICE after an isovolume exercise.

\section{Material and Methods}

\section{Participants}

Twelve physically active male subjects (age $23.22 \pm 5.47$ years, body height $1.73 \pm 0.06 \mathrm{~m}$, body mass $74.60 \pm 6.61 \mathrm{~kg}$, body mass index 24.63 $\pm 1.97 \mathrm{~kg} \cdot \mathrm{m}^{2-1}$ and peak oxygen uptake $58.58 \pm 5.60$ $\mathrm{ml} \cdot \mathrm{kg} \cdot \mathrm{min}^{-1}$ ) volunteered to participate in this study. They presented a health and neuromuscular status which demonstrated their ability to complete the study protocol. All procedures performed in the study were in accordance with the ethical standards of the University Research Ethics Committee of the São Paulo State University (UNESP) - Campus Presidente Prudente for studies involving human participants and followed the principles outlined in the Declaration of Helsinki. Written informed consent was obtained from all subjects after they had been informed about the purpose and risks of the study.

\section{Procedures}

Subjects completed three experimental trials in the laboratory. The first visit aimed to determine peak oxygen uptake $\left(\mathrm{VO}_{2 \max }\right)$ and the speed associated with $\mathrm{VO}_{2 \max }\left(\mathrm{sVO}_{2 \max }\right)$. During the remaining two visits, all subjects were submitted randomly to two $5 \mathrm{~km}$ running protocols on a treadmill: high-intensity interval exercise (HIIE) and moderate-intensity continuous exercise (MICE), separated by at least $72 \mathrm{~h}$. All tests took place at the same time of the day, between 1:00 p.m. and 6:00 p.m., at an average temperature of between 20 and $24^{\circ} \mathrm{C}$. The subjects were instructed to abstain from strenuous exercise for at least 24 hours prior to each exercise session, and maintain their usual nutritional and hydration routines. Moreover, they were also requested not to consume stimulants (tea, coffee, soda, chocolate, chocolate powder) or alcoholic 
beverages during this period.

Maximal endurance running test

The subjects were submitted to an incremental test on a treadmill (Inbramed MASTER CI, Inbrasport ${ }^{\circledR}$, Porto Alegre, Brazil). The test initial speed was $8 \mathrm{~km} \cdot \mathrm{h}^{-1}$, and increased by $1 \mathrm{~km} \cdot \mathrm{h}^{-1}$ every $2 \mathrm{~min}$ until volitional exhaustion. Strong verbal encouragement was given during the test. The oxygen uptake was measured (Quark PFT, Cosmed ${ }^{\circledR}$, Rome, Italy) throughout the test and the average of the final 30 seconds was defined as $\mathrm{VO}_{2 \max }$. The $\mathrm{sVO}_{2 \max }$ was assumed as the final incremental test speed. When the subject did not complete a stage, the speed was expressed according to the time spent in the final stage, determined as follow: $\mathrm{sVO}_{2 \max }=$ speed of the final complete stage + [(time, in seconds, remaining in the final incomplete stage / $120 \mathrm{~s}$ ) ${ }^{*} 1$ $\mathrm{km} \cdot \mathrm{h}^{-1}$ ] (Kuipers et al., 1985). In addition, the heart rate was recorded continuously throughout the tests (Polar Vantage NV, Electro Oy, Finland). The 6-20 Borg scale (Borg, 1982) was used to measure the rating of perceived exertion during the test.

High-intensity intermittent and moderateintensity continuous exercise

For both exercise trials, the subjects performed a warm-up consisting of running at $50 \%$ of $\mathrm{sVO}_{2 \max }$ for five minutes at a $1 \%$ inclination. The HIIE was performed intermittently with subjects running on a treadmill for one minute at $100 \%$ of $\mathrm{sVO}_{2 \text { Peak }}$ (Little et al., 2011), interspersed with one minute of passive recovery until they had completed 5 $\mathrm{km}$. The MICE consisted of continuous running of $5 \mathrm{~km}$ on the treadmill at $70 \%$ of $\mathrm{sVO}_{2 \max }$.

\section{Energy expenditure}

To estimate the energy expenditure of all exercises, the sum of the contribution of the three energy systems (aerobic, anaerobic lactic and alactic) was used. The aerobic metabolism was estimated using the oxygen uptake integral during the exercise, the anaerobic alactic was assessed using the fast phase of excess of oxygen uptake as described by Beneke et al. (2002) and the lactic anaerobic contribution using net blood lactate accumulation as proposed by Di Prampero and Ferretti (1999).

Oxygen uptake was measured continuously and for $60 \mathrm{~min}$ after the exercise protocols. At the 1st, 3rd, 5th and 7th min after the end of each test, blood samples were collected by venipuncture to measure lactate concentration. The highest lactate value ([La-]) measured was considered the peak lactate concentration ([La]peak). The difference between the [La-]peak and pre exercise lactate concentration ([La-]rest) was expressed as net lactate accumulation $(\Delta[\mathrm{La}-])$. A metabolic equivalent of $3 \mathrm{mLO} \cdot \mathrm{kg}^{-1}$ for each 1 $\mathrm{mmol} \cdot \mathrm{L}^{-1}$ of $\Delta[\mathrm{La}-]$ was considered as the anaerobic lactic contribution (Di Prampero and Ferretti, 1999).

For the anaerobic alactic contribution, the fast component of excess post-exercise oxygen consumption was determined using a modified bi-exponential decay equation. The anaerobic alactic contribution corresponded to the product of bi-exponential fast component amplitude and tau (Bertuzzi et al., 2007; Zagatto et al., 2011). The aerobic metabolism was estimated by subtracting rest oxygen consumption from exercise oxygen consumption. To estimate the total energy expenditure and oxygen consumption during each protocol, the energy expenditure were summed and converted to $\mathrm{kJ}$, assuming that $1 \mathrm{~L}$ of oxygen consumed was equivalent to $20.9 \mathrm{~kJ}$ (Gastin, 2001).

\section{Statistical Analysis}

Data normality was verified using the Shapiro-Wilk test and descriptive data are reported as means and standard deviation. The dependent $t$-test was used to compare the differences between the two protocols and Cohen's d was the calculated effect size.

The differences during the tests were analyzed by repeated measures analyses and the comparison between the MICE and HIIE was performed by two-way repeated measures ANOVA (group $x$ time). When a significant difference in group or interaction was observed, a Tukey post hoc test was conducted. For all measured variables, the estimated sphericity was verified according to the Mauchly's W test, and the Greenhouse-Geisser correction was used when necessary. The effect size (eta-squared; $\eta^{2}$ ) of each test was calculated for all analyses. Statistical significance was set at $p<0.05$. The data were analyzed using Biostat (version 5.0).

\section{Results}

The characteristics and anthropometric measures of the subjects, in addition to a summary of the incremental test, are shown in 
Table 1.

A summary of both exercise protocols is shown in Table 2. Significant differences were found for HIIE compared to MICE $(p=0.01$, Cohen's $d=1.07)$ for total speed and exercise session duration.

Figure 1 presents the difference in [La-] between the MICE and HIIE. There was a statistically significant difference across time as well as 30, 45 and 60 minutes after the exercise session with higher values in the HIIE $(p<0.001$, $\eta^{2}=0.69$ ). Furthermore, there was a statistically significant difference between the MICE and HIIE groups $\left(p=0.001, \eta^{2}=0.66\right)$ and an interaction was observed (time $\mathrm{x}$ group: $p<0.001, \eta^{2}=0.38$ ).

Figure 2 shows the differences in $\mathrm{VO}_{2}$ consumption during 30 minutes of exercise and 30, 45 and 60 minutes after the exercise cessation in both conditions.

There was a statistically significant difference across time in $\mathrm{VO}_{2}\left(p<0.001, \eta^{2}=0.98\right)$. Post hoc analysis revealed that at the 10th and 30th min of exercise, there was a difference in HIIE compared to at rest and the 5th min. All groups presented a difference compared to rest. After 30, 45 and 60 minutes of exercise cessation, $\mathrm{VO}_{2}$ was different from all moments during exercise for both groups and returned to baseline values. There was an interaction (time $x$ group: $\left.p=002, \quad \eta^{2}=0.41\right)$ with significant differences between groups at the 30th min of exercise ( $p=$ $0.044, \eta^{2}=0.59$ ).

When analyzing the HR and RPE (Figure $3)$, there were significant differences across time (HR: $p<0.001, \eta^{2}=0.98$; RPE: $p=0.001, \eta^{2}=0.80$ ), between groups (HR: $p=0.038 ; \eta^{2}=0.92$; RPE: $p=$ $0.002 ; \eta^{2}=0.66$ ) and interaction (time $x$ group, HR: $p=0.003, \eta^{2}=0.75$; RPE: $p<0.001, \eta^{2}=0.92$ ).

Both aerobic and lactic anaerobic contributions were higher during HIIE than MICE $(p=0.88)$, while alactic anaerobic contributions were not different (Table 3). Furthermore, HIIE presented higher total energy expenditure $(p=$ 0.003 , Cohen's $d=0.65)$ and EPOC $(p=0.03$, Cohen's d $=0.58$ ).

HIIE presented higher values for the [La-] area under the curve $(293 \pm 123.98$ a.u.) than MICE (120.44 \pm 53.0 a.u.), however, when the rest period of HIIE was controlled (Minganti et al., 2011), there was no difference found between the conditions (150.53 \pm 62.73 a.u. and $120.44 \pm 53.0$ a.u., respectively; $p=0.13$ ).

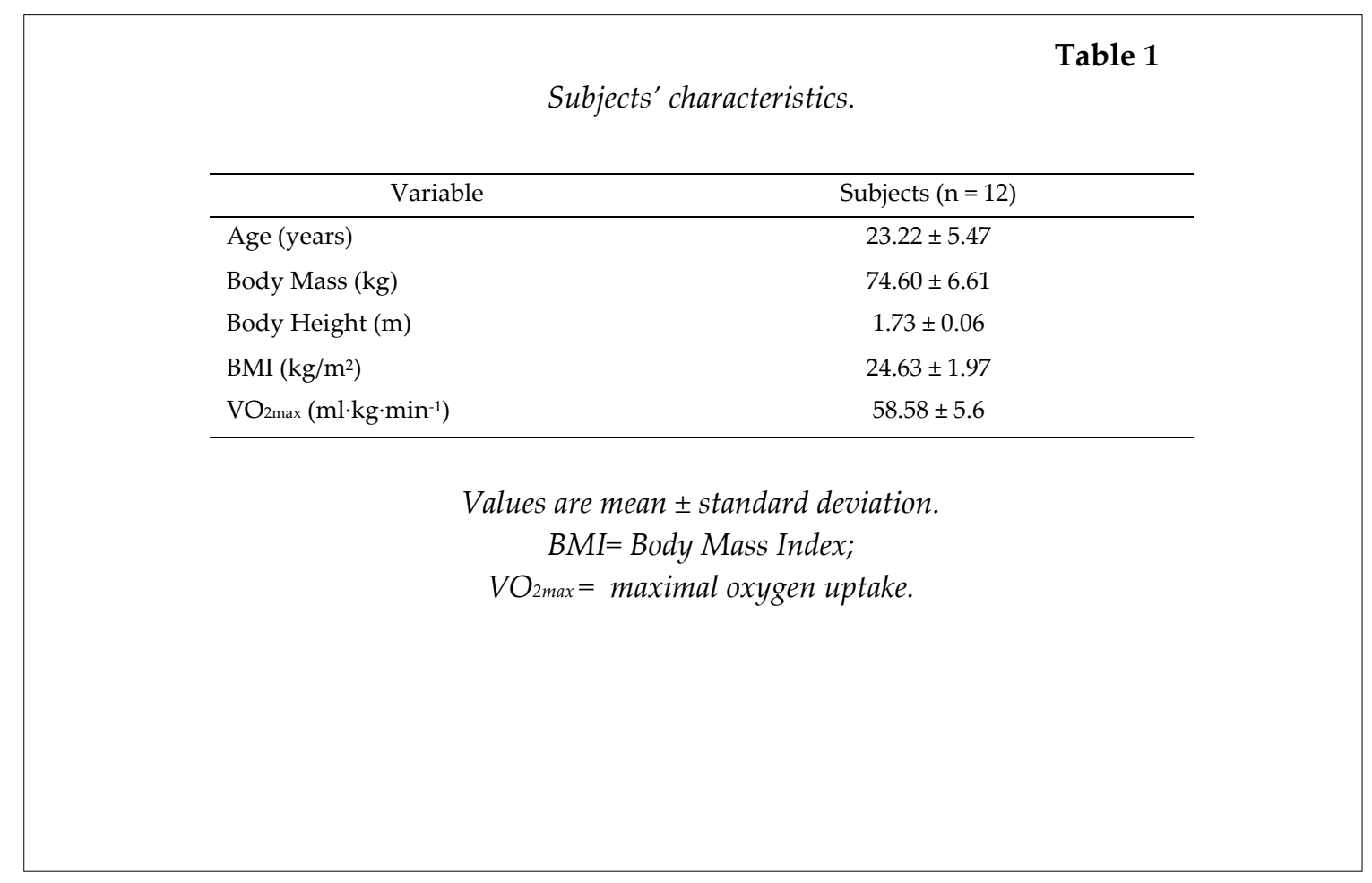


Table 2

Summary of exercise descriptors for high-intensity exercise (HIIE) and moderate-intensity continuous exercise (MICE) protocols ( $n=12$ ).

\begin{tabular}{lcc}
\hline \multicolumn{1}{c}{ Variable } & MICE & HIIE \\
\hline Protocol & run at $70 \% \mathrm{sVO}_{2 \max }$ & $1: 1$-minute at $100 \% \mathrm{sVO}_{2 \max }$ \\
Speed $\left(\mathrm{km} \cdot \mathrm{h}^{-1}\right)$ & $10.14 \pm 0.84$ & $14.23 \pm 1.20^{*}$ \\
Exercise session (min) & $29.77 \pm 2.46$ & $21.07 \pm 1.78^{*}$ \\
Total exercise duration (min) & $29.77 \pm 2.46$ & $41.14 \pm 3.56^{*}$ \\
\hline
\end{tabular}

Values are mean \pm standard deviation.

* = significant differences from MICE $(p<0.05)$.

Table 3

Mean \pm standard deviation of aerobic, anaerobic lactic and alactic contribution, total energy expenditure, and excess post oxygen consumption during moderate intensity continuous exercise, and high intensity interval exercise $(n=12)$.

\begin{tabular}{ccc}
\hline \multicolumn{1}{c}{ Variable } & MICE & HIIE \\
\hline Aerobic contribution & $83.66 \pm 11.28$ & $96.59 \pm 8.23^{*}$ \\
L & $1748.47 \pm 235.73$ & $2018.66 \pm 172.04^{*}$ \\
kJ & & \\
Anaerobic alactic contribution & $1.68 \pm 0.28$ & $1.64 \pm 0.50$ \\
L & $35.11 \pm 5.81$ & $34.28 \pm 10.35$ \\
kJ & & \\
Anaerobic lactic contribution & $0.64 \pm 0.67$ & $1.27 \pm 0.76^{*}$ \\
L & $13.33 \pm 13.93$ & $26.59 \pm 15.78^{*}$ \\
kJ & & $100.19 \pm 8.15^{*}$ \\
Total energy expenditure & $88.35 \pm 11.46$ & $2094.06 \pm 170.27^{*}$ \\
L & $1846.60 \pm 239.50$ & $6.61 \pm 1.85^{*}$ \\
kJ & & $138.21 \pm 38.69^{*}$ \\
EPOC & $5.32 \pm 2.39$ & \\
L & $111.19 \pm 49.97$ & \\
kJ & &
\end{tabular}

MICE: moderate intensity continuous exercise; HIIE: high intensity interval exercise;

EPOC: excess post-exercise oxygen consumption.

* significantly different from MICE. 


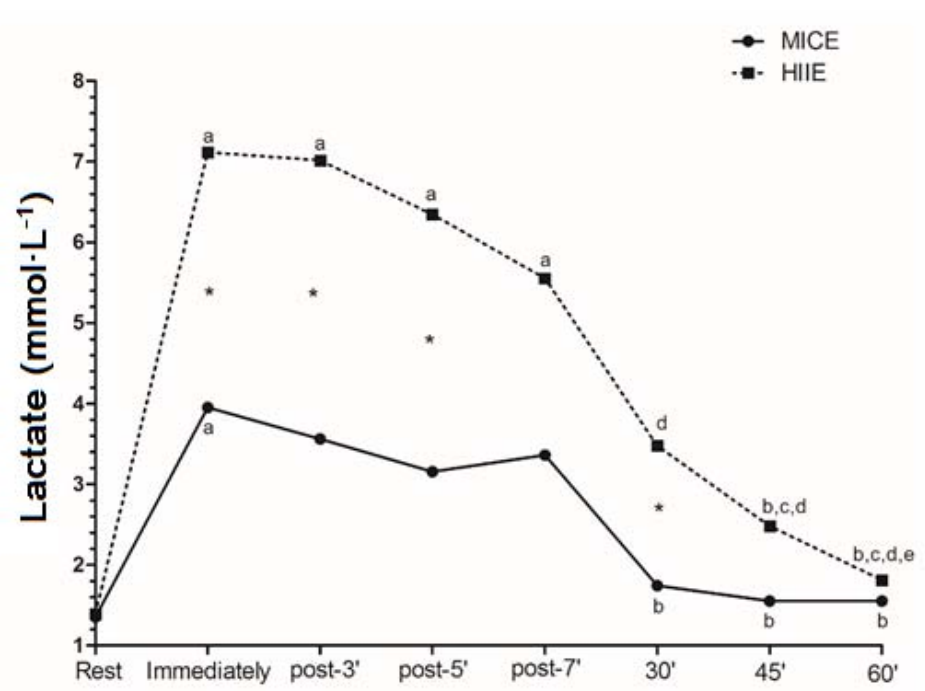

Figure 1

Difference on [La-] between MICE and HIIE.

Legend: $a=$ Tukey's post-hoc test with $p<0.05$ compared to rest;

$b=$ Tukey's post-hoc test with $p<0.05$ compared to immediately post-exercise;

$c=$ Tukey's post-hoc test with $p<0.05$ compared to post 3 min;

$d=$ Tukey's post-hoc test with $p<0.05$ compared to post $5 \mathrm{~min}$;

$e=$ Tukey's post-hoc test with $p<0.05$ compared to post 7 min;

* statistically significant difference between MICE and HIIE.

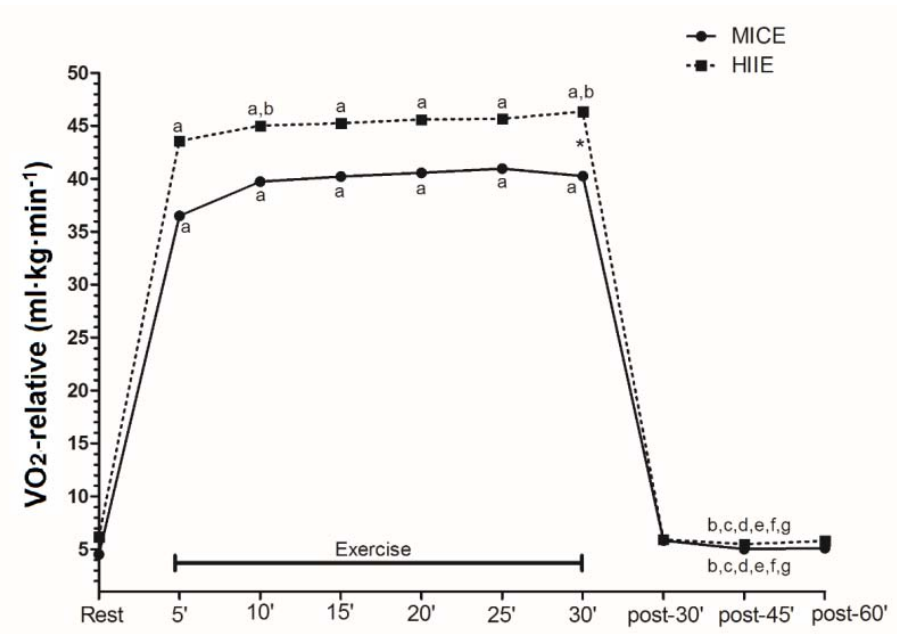

Figure 2

Difference on oxygen uptake (VO2relative) between MICE and HIIE.

Legend: $a=$ Tukey's post-hoc test compared to rest;

$b=$ Tukey's post-hoc test compared to five minutes of exercise;

$c=$ Tukey's post-hoc test with compared to 10 min of exercise;

$d=$ Tukey's post-hoc test with compared to 15 min of exercise;

$e=$ Tukey's post-hoc test with compared to 20 min of exercise;

$f=$ Tukey's post-hoc test compared to 25 min of exercise;

$g=$ Tukey's post-hoc test compared to 30 min of exercise;

* = statistically significant difference between MICE and HIIE; $p<0.05$ 
A

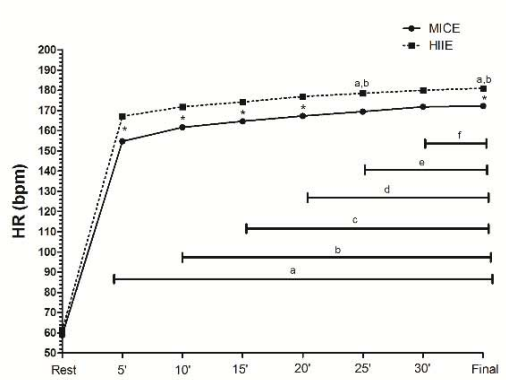

B

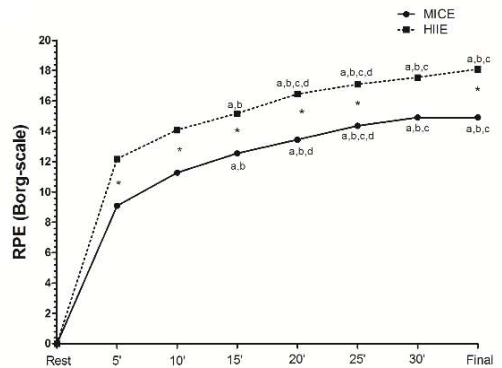

Figure 3

Difference on the rating of perceived exertion (RPE) and heart rate

(HR) between MICE and HIIE.

Legend: For RPE: $a=$ Tukey's post-hoc test compared to five min of exercise;

$b=$ Tukey's post-hoc test compared to 10 min of exercise;

$c=$ Tukey's post-hoc test compared to 15 min of exercise;

$d=$ Tukey's post-hoc test compared to 20 min of exercise. For HR:

$a=$ Tukey's post-hoc test compared to rest;

$b=$ Tukey's post-hoc test compared to five min of exercise;

$c=$ Tukey's post-hoc test compared to 10 min of exercise;

$d=$ Tukey's post-hoc test compared to 15 min of exercise;

$e=$ Tukey's post-hoc test compared to 20 min of exercise;

$f=$ Tukey's post-hoc test compared to 25 min of exercise;

$g=$ Tukey's post-hoc test compared to 30 min of exercise;

* = statistically significant difference between MICE and HIIE; $p<0.05$

\section{Discussion}

This study aimed to compare physiological response after an iso-volume HIIE and MICE in physically active subjects. In accordance with our hypothesis, the same volume HIIE induced a higher RPE, HR and post [La-] than MICE, however, $\mathrm{VO}_{2}$ was higher only at the end of exercise. In addition, aerobic and lactic anaerobic contributions, total energy expenditure and EPOC were higher during HIIE than MICE.

High intensity interval training and all-out maximum effort or capacity have been used to promote weight loss, glycemic control and increases in aerobic fitness (Burgomaster et al., 2008; Gibala et al., 2012; Little et al., 2011; Panissa et al., 2016). However, all-out exercise needs specific equipment (cycloergometer, i.e., mechanically braked bicycle ergometer, or if performed outdoors, a field or running track), and may be unattainable for some populations, limiting its feasibility. Thus, high intensity interval training seems to be an interesting way to overcome this limitation (Skelly et al., 2014).

As expected, the HR and a consequently increasing RPE were higher during HIIE than MICE, since a linear relationship exists between the HR and exercise intensity (Karvonen and Vuorimaa, 1988). In addition, [La-]peak was higher after the HIIE than the MICE, however, even the MICE presented mean [La-] values close to the anaerobic threshold immediately after the exercise $\left(4.74 \pm 2.43 \mathrm{mmol} \cdot \mathrm{L}^{-1}\right)$, while the HIIE presented the values of $8.25 \pm 2.95 \mathrm{mmol} \cdot \mathrm{L}^{-1}$. This result indicates a higher contribution of the 
anaerobic metabolism during the HIIE in comparison with the MICE. The present study revealed that even though the HR was higher during HIIE, the $\mathrm{VO}_{2}$ response was not (Figure 2). However, taking into account the aerobic contribution during the exercise, HIIE presented a greater amount of consumed oxygen which may have occurred due to the longer exercise time (Table 2). Thus, since $\mathrm{VO}_{2}$ consumption (perceptual in relation to $\mathrm{VO}_{2 \max }$ ) during exercise training is one important index to characterize the aerobic training stimulus (Buchheit and Laursen, 2013; Zagatto et al., 2011), the HIIE was more effective in stimulating the aerobic metabolism compared with the MICE. Nevertheless, the exercise time must be considered. When the HIIE exercise time is matched for the MICE, the $\mathrm{VO}_{2}$ integral of HIIE is significantly lower than MICE $(68.07 \pm 6.19 \mathrm{~L}$ and $83.66 \pm 11.28 \mathrm{~L}$, respectively; $p$ $=0.0001)$, indicating that for isotime exercise, in continuous $5 \mathrm{~km}$ running at $70 \%$ of $\mathrm{sVO}_{2 \max }$ the cumulative $\mathrm{O}_{2}$ cost is higher than in HIIE (with the same exercise session time); however, we cannot assume whether after exercise, energy expenditure (i.e. EPOC) would be different or not. Therefore, future studies should investigate whether it is more important to exercise at high intensity or to maintain a longer time of exercise at moderate intensity.

Several studies have compared the effects of high and moderate intensity training on physical fitness; however, various intensities have been used to compare training exercises (Gillen et al., 2013; Skelly et al., 2014; Trapp et al., 2008; Williams et al., 2013). In relation to moderate training, high intensity training has been proposed to present higher or similar physical fitness adaptations (Buchheit and Laursen, 2013; Gibala et al., 2006; Wisløff et al., 2007), however, intensity used in the MICE may also influence the results. Aiming to compare HIIE and MICE, Skelly et al. (2014) used $77 \%$ and $33 \%$ of peak power output, respectively, which is considerably lower than the intensity used in the present study $\left(100 \%\right.$ and $70 \%$ of $\mathrm{sVO}_{2 \max }$ ). While for our subjects, $70 \%$ of $\mathrm{sVO}_{2 \max }$ could have been at or slightly above the anaerobic threshold and the mean exercise HR was $86.20 \pm 2.76 \%$ of the maximal HR, much higher than other moderate intensity training protocols (Burgomaster et al., 2008; Gibala et al., 2012; Sperlich et al., 2011; Williams et al., 2013). Thus, the assumption that training consisting of HIIE is better than MICE to improve physiological responses must be considered with caution since MICE intensity is usually too low to induce high adaptations. Other studies may want to verify whether at or above the anaerobic threshold moderate intensity training induces similar adaptations to high intensity interval training.

The analysis of the recovery period has also been proposed to be important regarding the effects of different types of training on physical fitness (Skelly et al., 2014; Williams et al., 2013). Skelly et al. (2014) did not observe any difference in EPOC after HIIE and MICE in physically active subjects, however, MICE intensity was too low to induce higher EPOC and HIIE presented low volume, hampering the comparison with the present study. Tucker et al. (2016) compared HIIE (four bouts of $4 \mathrm{~min}$ intervals at $95 \%$ of the peak heart rate, with 3 min of active recovery), MICE (30 $\mathrm{min}$ at $80 \%$ of $\mathrm{HR}_{\text {peak }}$ ) and sprint interval exercise (SIE) (six $30 \mathrm{~s}$ Wingate sprints, separated by $4 \mathrm{~min}$ of recovery periods) in active men and although SIE elicited greater EPOC, no differences were registered in total energy expenditure compared to HIIE and MICE. This suggests that this is unlikely to be the mechanism contributor to body composition changes. In our study, EPOC following HIIE was significantly higher compared to MICE, however, this difference was small and the result could have been similar if the exercise duration was the same. This is yet to be determined.

In addition to exercise volume (external load), and intensity (i.e., RPE, [La-], or HR; (internal load)), their product (i.e., training impulse - TRIMP) must also be taken into account (Borresen and Lambert, 2008a; Borresen and Lambert, 2008b; Foster et al., 2011; Manzi et al., 2009; Minganti et al., 2011). Although some studies have equalized exercise energy expenditure (Gibala et al., 2012), the training impulse (product between the external and internal load) was not considered when comparing exercise training. Thus, it is still important to determine (i) whether physiological differences exist between HIIE and MICE when the training impulse is equalized and (ii) whether a passive resting period may have to be taken into account when calculating the training impulse. 
Recent research suggests that HIIE is a time-efficient exercise strategy (Gillen and Gibala, 2014) when compared to MICE. These results are in agreement with our findings, however, it should be noted that longer exercise duration was required to accomplish the same distance of running with HIIE compared to MICE. This is a possible limitation when applying the results of this study to practice, as the effective training duration for HIIE was approximately $28 \%$ longer when including the recovery intervals. Moreover, the energy expenditure was $13 \%$ higher in HIIE than MICE to complete the same distance.

In conclusion, HIIE was more effective at modifying the HR and RPE. Oxygen uptake was higher only at the end of exercise, even though
HIIE presented greater aerobic contribution (Table 3), thus, total session duration may have influenced our results(MICE: $29.77 \pm 2.46$ minutes; HIIE: $41.14 \pm 3.56$ minutes). Furthermore, when the exercise time was relativized, no difference existed in the aerobic contribution between HIIE and MICE. After exercise cessation, EPOC was higher in HIIE, but the differences were quantitatively small. Thus, equalizing the training impulse or time of exercise could induce different results. The practical application of these findings can be used to help design physical training programs for all populations, due to the easily accessible benefits from proper implementation.

\section{Acknowledgements}

This work was supported by the Fundação de Amparo à Pesquisa do Estado de São Paulo (FAPESP, Brazil) under Grant no 2013/25310-2.

\section{References}

Beneke R, Pollmann C, Bleif I, Leithäuser RM, Hütler M. How anaerobic is the Wingate Anaerobic Test for humans? Eur J Appl Physiol, 2002; 87: 388-392

Bertuzzi RC, Franchini E, Kokubun E, Kiss MA. Energy system contributions in indoor rock climbing. Eur J App Physiol, 2007; 101: 293-300

Borg Gunn AR. Psychophysical bases of perceived exertion. Med Sci Sports Exerc, 1982; 14: 877

Borresen J, Lambert MI. Autonomic control of heart rate during and after exercise: measurements and implications for monitoring training status. Sports Med, 2008; 38: 633-46

Borresen J, Lambert MI. Quantifying training load: a comparison of subjective and objective methods. Int J Sports Physiol Perform, 2008; 3: 16

Buchheit M, Laursen PB. High-intensity interval training, solutions to the programming puzzle: Part I: cardiopulmonary emphasis. Sports Med, 2013; 43: 313-38

Burgomaster KA, Howarth KR, Phillips SM, Rakobowchuk M, Macdonald MJ, McGee SL, Gibala MJ. Similar metabolic adaptations during exercise after low volume sprint interval and traditional endurance training in humans. J Physiol, 2008; 586: 151-160

di Prampero PE, Ferretti G. The energetics of anaerobic muscle metabolism: a reappraisal of older and recent concepts. Respir Physiol, 1999; 118: 103-115

Foster C, Florhaug JA, Franklin J, Gottschall L, Hrovatin LA, Parker S, Doleshal P, Dodge C. A new approach to monitoring exercise training. J Strength Cond Res, 2001; 15: 109-115

Garber CE, Blissmer B, Deschenes MR, Franklin BA, Lamonte MJ, Lee IM, Nieman DC, Swain DP. American College of Sports Medicine position stand. Quantity and quality of exercise for developing and maintaining cardiorespiratory, musculoskeletal, and neuromotor fitness in apparently healthy adults: guidance for prescribing exercise. Med Sci Sports Exerc, 2011; 43: 1334-1359

Gastin PB. Energy system interaction and relative contribution during maximal exercise. Sports Med, 2001; 31: 725-741 
Gibala MJ, Little JP, Macdonald MJ, Hawley JA. Physiological adaptations to low-volume, high-intensity interval training in health and disease. J Physiol, 2012; 590: 1077-1084

Gibala MJ, Little JP, van Essen M, Wilkin GP, Burgomaster KA, Safdar A, Raha S, Tarnopolsky MA. Shortterm sprint interval versus traditional endurance training: similar initial adaptations in human skeletal muscle and exercise performance. J Physiol, 2006; 575: 901-911

Gillen JB, Percival ME, Ludzki A, Tarnopolsky MA, Gibala MJ. Interval training in the fed or fasted state improves body composition and muscle oxidative capacity in overweight women. Obesity, 2013; 21: 2249-2255

Gillen JB, Gibala MJ. Is high-intensity interval training a time-efficient exercise strategy to improve health and fitness? Appl Physiol Nutr Metab, 2014; 39: 409-412

Haskell WL, Lee IM, Pate RR, Powell KE, Blair SN, Franklin BA, Macera CA, Heath GW, Thompson PD, Bauman A. Physical activity and public health: updated recommendation for adults from the American College of Sports Medicine and the American Heart Association. Med Sci Sports Exerc, 2007; 39: 1423-1434

Ismail I, Keating SE, Baker MK, Johnson NA. A systematic review and meta-analysis of the effect of aerobic vs. resistance exercise training on visceral fat. Obes Rev, 2012; 13: 68-91

Karvonen J, Vuorimaa T. Heart rate and exercise intensity during sports activities. Practical application. Sports Med, 1988; 5: 303-311

Kelley GA, Kelley KS. Effects of aerobic exercise on C-reactive protein, body composition, and maximum oxygen consumption in adults: a meta-analysis of randomized controlled trials. Metabolism, 2006; 55: 1500-507

Kelley GA, Kelley KS. Efficacy of aerobic exercise on coronary heart disease risk factors. Prev Cardiol, 2008; 11: 71-75

Kuipers H, Verstappen FT, Keizer HA, Geurten P, van Kranenburg G. Variability of Aerobic Performance in the Laboratory and Its Physiologic Correlates. Int J Sports Med, 1985; 6: 197-201

Little JP, Gillen JB, Percival ME, Safdar A, Tarnopolsky MA, Punthakee Z, Jung ME, Gibala MJ. Low-volume high-intensity interval training reduces hyperglycemia and increases muscle mitochondrial capacity in patients with type 2 diabetes. J Appl Physiol, 2011; 111: 1554-1560

Manzi V, Iellamo F, Impellizzeri F, D'Ottavio S, Castagna C. Relation between individualized training impulses and performance in distance runners. Med Sci Sports Exerc, 2009; 41: 2090-2096

Minganti C, Ferragina A, Demarie S, Verticchio N, Meeusen R, Piacentini MF. The use of session RPE for interval training in master endurance athletes: should rest be included? J Sports Med Phys Fitness, 2011; 51: 547-554

Nelson ME, Rejeski WJ, Blair SN, Duncan PW, Judge JO, King AC, Macera CA, Castaneda-Sceppa C. Physical activity and public health in older adults: recommendation from the American College of Sports Medicine and the American Heart Association. Med Sci Sports Exerc, 2007; 39: 1435-1445

Ozyener F, Rossiter HB, Ward SA, Whipp BJ. Influence of exercise intensity on the on- and off-transient kinetics of pulmonary oxygen uptake in humans. J Physiol, 2001; 533: 891-902

Panissa VLG, Alves ED, Salermo GP, Franchini E, Takito MY. Can short-term high-intensity intermittent training reduce adiposity? Sport Sci Health, 2016; 12: 99-104

Skelly LE, Andrews PC, Gillen JB, Martin BJ, Percival ME, Gibala MJ. High-intensity interval exercise induces 24-h energy expenditure similar to traditional endurance exercise despite reduced time commitment. Appl Physiol Nutr Metab, 2014; 39: 845-848

Sperlich B, De Marées M, Koehler K, Linville J, Holmberg HC, Mester J. Effects of 5 weeks of high-intensity interval training vs. volume training in 14-year-old soccer players. J Strength Cond Res, 2011; 25: 12711278

Thorogood A, Mottillo S, Shimony A, Filion KB, Joseph L, Genest J, Pilote L, Poirier P, Schiffrin EL, 
Eisenberg MJ. Isolated aerobic exercise and weight loss: a systematic review and meta-analysis of randomized controlled trials. Am J Med, 2011; 124: 747-755

Tucker WJ, Angadi SS, Gaesser GA. Excess Postexercise Oxygen Consumption After High-Intensity and Sprint Interval Exercise, and Continuous Steady-State Exercise. J Strength Cond Res, 2016; 30: 3090-3097

Trapp EG, Chisholm DJ, Freund J, Boutcher SH. The effects of high-intensity intermittent exercise training on fat loss and fasting insulin levels of young women. Int J Obes, 2008; 32: 684-691

Whyte LJ, Gill JM, Cathcart AJ. Effect of 2 weeks of sprint interval training on health-related outcomes in sedentary overweight/obese men. Metabolism, 2010; 59: 1421-1428

Williams CB, Zelt JG, Castellani LN, Little JP, Jung ME, Wright DC, Tschakovsky ME, Gurd BJ. Changes in mechanisms proposed to mediate fat loss following an acute bout of high-intensity interval and endurance exercise. Appl Physiol Nutr Metab, 2013; 38: 1236-44

Wisløff U, Støylen A, Loennechen JP, Bruvold M, Rognmo Ø, Haram PM, Tjønna AE, Helgerud J, Slørdahl SA, Lee SJ, Videm V, Bye A, Smith GL, Najjar SM, Ellingsen Ø, Skjaerpe T. Superior cardiovascular effect of aerobic interval training versus moderate continuous training in heart failure patients: a randomized study. Circulation, 2007; 115: 3086-3094

Zagatto A, Redkva P, Loures J, Kalva Filho C, Franco V, Kaminagakura E, Papoti M. Anaerobic contribution during maximal anaerobic running test: correlation with maximal accumulated oxygen deficit. Scandinavian J Med \& Sci Sports, 2011; 21: 222-2230

\section{Corresponding author:}

\section{Eduardo Zapaterra Campos}

Department of Physical Education - Universidade Federal de Pernambuco Avenida Professor Moraes Rego, 1235, CEP 5670-901, Recife, PE, Brazil.

Phone: 558121268000

E-mail address: zacampos@yahoo.com.br 